\title{
'He cut-break the rope': Encoding and categorizing cutting and breaking events in Mandarin
}

JIDONG CHEN*

\section{Abstract}

Mandarin categorizes cutting and breaking events on the basis of fine semantic distinctions in the causal action and the caused result. I demonstrate the semantics of Mandarin $C \& B$ verbs from the perspective of event encoding and categorization as well as argument structure alternations. Three semantically different types of predicates can be identified: verbs denoting the $C \& B$ action subevent, verbs encoding the $C \& B$ result subevent, and resultative verb compounds $(R V C)$ that encode both the action and the result subevents. The first verb of an $R V C$ is basically dyadic, whereas the second is monadic. RVCs as a whole are also basically dyadic, and do not undergo detransitivization.

Keywords: cut and break; separation events; verb semantics; Mandarin; resultative verb compounds; event encoding; categorization; argument structure.

\section{Introduction}

A cutting and breaking event (henceforth C\&B event), as typically described by an English monomorphemic verb like cut, in He cut the rope, is typically encoded in Mandarin with a resultative verb compound (henceforth RVC) such as qiel-duan4 'cut.with.single.blade-be.broken' ${ }^{1}$ in (1):
(1) Ta1 qie1-duan4
le shen $2 z i^{2}$.
he cut.with.single.blade-be.broken PFV rope
'He cut the rope.'

The first verb $\left(\mathrm{V}_{1}\right)$ of the RVC, qiel, encodes only the sub-event of the cutting action while the second verb $\left(\mathrm{V}_{2}\right)$, duan4, encodes the state change of being broken that results from the cutting action. In Mandarin there is a range of simplex $C \& B$ action verbs and result verbs ${ }^{3}$ that encode and categorize each sub-event on the basis of fine semantic distinctions. 
In the crosslinguistic sample represented in this special issue, Mandarin stands out for its compositional way of encoding a $\mathrm{C} \& \mathrm{~B}$ event with two separate verbs, each with distinct lexical semantics. In this chapter I discuss the lexical semantics of $C \& B$ verbs and the semantic distinctions that Mandarin speakers make when they talk about $C \& B$ events. I show that Mandarin supports the proposed universal distinction between C\&B verbs (Guerssel et al. 1985; Levin and Rappaport Hovav 1995), but Mandarin $\mathrm{C} \& \mathrm{~B}$ verbs differ crucially from the English cut and break in their semantics and argument structure, and the two-way distinction of C\&B verbs should be broadened to include a third type of $C \& B$ verb, the RVC. I also show that the semantics of Mandarin C\&B verbs play a role in their argument structure alternation possibilities. The data used in examining event categorization were elicited descriptions of 43 videoclips ${ }^{4}$ depicting C\&B events (Bohnemeyer et al. 2001; for a full description of the stimulus set see Majid et al., this issue) by six adult native speakers of Mandarin (mean age 28) and the argument structure data are based on my own intuitions as a native Mandarin speaker, as well as elicited descriptions from and consultations with other adult native speakers.

\section{Encoding C\&B with RVCs: The lexical semantics of RVCs}

Mandarin has few monomorphemic verbs that-like English cut and break-lexicalize both a causal action and a caused state change. Instead, it employs a very productive process of combining two simplex verbs in an RVC. The productivity of verb compounding was attested by the diversity of RVCs used in the descriptions of C\&B events by the six consultants: a total 43 types of RVCs were produced (token frequency of 246). This productivity is also revealed by the flexibility of combining different action verbs with the same result verb, e.g., bail-duan4 'bendbe.broken', bail-sui4 'bend-be.in.pieces', bail-zhe2 'bend-be.bent', and conversely of combining different result verbs with the same action verb, e.g., qiel-duan4 'cut.with.single.blade-be.broken', jian3-duan4 'cut. with.scissor-(like).instrument-be.broken', ju4-duan4 'cut.with.saw-(like). instrument-be.broken'.

C\&B RVCs are semantically compositional. As a whole, they entail a state change, which is indefeasible, as shown in (2):

(2) \#

Tal

qie1-duan4

le shen2zi, ke3shi4, shen2zi,

he cut.with.single.blade-be.broken PFV rope, but, rope,

mei2 duan4.

not be.broken

'He cut the rope but it didn't break.' 
In (2), the RVC qiel-duan4 entails a state change of being broken, but this is then contradicted by the statement in the second clause that the stick did not break.

An RVC, by its composition $\left(\mathrm{V}_{1} \mathrm{~V}_{2}\right)$, clearly represents a causal event as composed of two sub-events, each represented by one verb. There is no morphological marking indicating the relationship between the constituent verbs (Chao 1968; Li and Thompson 1981). The ordering of the two verbs is rigid and iconic - the verb expressing the causal act always precedes the verb expressing the state change. The NP specifying the affected object (if expressed) follows the whole verb compound, and no NP can intervene between the constituent verbs-(3) is ungrammatical:

$\begin{array}{llll}\text { *Tal qie1 } & \text { shen2zi } & \text { duan4 } & l e . \\ \text { he cut.with.single.blade } & \text { rope } & \text { be.broken } & \text { PFV } \\ \text { 'He cut the rope broken.' } & & & \end{array}$

The component verbs, $\mathrm{V}_{1}$ and $\mathrm{V}_{2}$, can be used independently as full verbs. However, the use of $\mathrm{V}_{1}$ or $\mathrm{V}_{2}$ alone captures only one aspect of a $\mathrm{C} \& \mathrm{~B}$ event, i.e., the cause $\left(\mathrm{V}_{1}\right)$ or the result $\left(\mathrm{V}_{2}\right)$ component, as in (4a) and (4b):
a. Tal qie1 le shen2zi. he cut.with.single.blade PFV rope 'He did cutting at the rope.'
b. Shen2zi duan4 le. rope be.broken PFV 'The rope was broken.'

In my data RVCs were the most frequent predicates, accounting for $89 \%$ of predicates. The remaining $11 \%$ of predicates were action verbs alone. There was no use of result verbs alone.

The $\mathrm{V}_{1}$ in an RVC in itself either does not make any assertion about a state change, e.g., soul 'hunt' ("moot fulfillment" verbs in Talmy's 2000 terminology), or it implies but does not entail the state change, e.g., xi3 "wash' ("implied fulfillment" verbs, Talmy 2000). So the state change that is entailed by a monomorphemic verb like cut or break in English is defeasible for Mandarin C\&B action verbs, as in (5):

$\begin{array}{llllll}\text { Wo3 qie1 } & \text { le } & \text { shen2zi, } & \text { ke3shi4 } & \text { shen2zi mei2 } \\ \text { I cut.with.single.blade } & \text { PFV } & \text { rope, } & \text { but } & \text { rope not } \\ \text { duan4. } & & & & & \end{array}$

be.broken

'I cut the rope but it didn't break.' (i.e., there was no separation in the rope) 
Typologically, Mandarin and English differ in their lexicalization of state change (Talmy 2000). Mandarin C\&B action verbs encode the causal sub-event and leave lexicalization of the resulting event to an additional verb. This lexicalization pattern is reflected in a Mandarin speaker's description of one videoclip in which an agent bent a stick until it cracked:

Ta1 bail le gun2zi, ke3shi4 mei2 bail-duan4
he bend PFV stick, but not bend-be.broken
bail-zhe 2 le.
bend-be.bent PFV
'He bent the stick, but didn't break it. He only made it bent.'

In (6), $\mathrm{V}_{1}$, bail 'bend.by.hand(-like).instrument's, encodes the nature of the pressure exerted on the stick but does not specify anything about the result, e.g., becoming bent. It is the $\mathrm{V}_{2}$ that confirms the actual state change, duan 4 'be.broken (of long object crosswise)' or zhe2 'be.bent'. In contrast, English monomorphemic C\&B verbs lexicalize-hence, entailthe resulting event. To eliminate the entailed state change meaning or reduce it to the status of moot fulfillment, English typically resorts to progressive aspect, as in He is cutting the rope, or a conative construction, as in He cut at the rope. Mandarin, on the other hand, uses simplex action verbs, as in wo3 qiel le shen $2 z i$ 'I cut.with.single.blade PFV rope' (= I did a cutting action on the rope).

Although Mandarin C\&B RVCs can be regarded as the semantic counterparts of English $\mathrm{C} \& \mathrm{~B}$ verbs, they differ in their Aktionsart. Both English C\&B verbs and Mandarin C\&B RVCs are telic. But the former are compatible with progressive aspect, the use of which switches the focus to the process leading up to the state change. In contrast, Mandarin C\&B RVCs are incompatible with progressive aspect: they focus only on the endpoint of the event (Tai 1984), and they present the event as a nondecomposable whole ( $\mathrm{Li}$ and Shirai 2000; Smith 1997). The progressive aspect marker zai4 makes explicit reference to the internal structure of a situation. Since Mandarin RVCs mark events as completed state changes, it is impossible to use zai4 to mark an on-going process that leads to a result.

\section{Categorization of $C \& B$ events}

What semantic distinctions are drawn by Mandarin C\&B verbs? To address this question, I applied correspondence analysis (Greenacre 1984; Majid et al., this issue) separately to $\mathrm{V}_{1} \mathrm{~s}$ (action verbs) and $\mathrm{V}_{2} \mathrm{~s}$ (result verbs). Correspondence analysis is a method for exploring which stimuli the participants think of as similar, and also which verbs they use in a similar way. In this method, the similarity of stimuli is assessed by 
determining how similarly consultants label them. For example, two stimuli that are described unanimously with the same verb(s) by all consultants are completely similar, two that are never described with the same verb(s) by any consultant are completely dissimilar, and two that are labeled with the same verb(s) by some speakers but not others are intermediate in similarity. The distribution of verbs across stimuli can also be used to assess the similarity of the verbs: verbs are taken to be semantically similar to the extent that they are used for the same stimuli. The similarity of the stimuli to each other, and of the verbs to each other, is displayed in terms of physical closeness in a multidimensional space: the more similar two stimuli or two verbs are, the closer together they fall. The following sections summarize the main results from the correspondence analyses of C\&B verbs (see Majid et al., this issue, for details of this method).

\subsection{Semantics of $C \& B$ action verbs $\left(V_{1} s\right)$}

Correspondence analysis revealed five distinct clusters of $\mathrm{C} \& \mathrm{~B}$ causal events and the Mandarin verbs used to describe them:

(1) Cutting with scissor(-like) (two-bladed) instrument (e.g., nail-clippers, pliers). This forms the most distinct group in the analysis; it comprises events that were consistently labeled with the action verb jian3 'cut.with.scissor(-like).instrument'. Interestingly, this distinction is not universal: in the 28-language sample on which this special issue is based, only five languages, Mandarin, Dutch, Swedish, Tidore, and Otomi, make such a distinction. In Mandarin, it is obligatory to use jian 3 for $\mathrm{C} \& \mathrm{~B}$ events involving cutting with double blades.

(2) Cutting with a single-blade(-like) instrument (e.g., knife, machete, axe, edge of hand, wire). These events are labeled by ten verbs that share the 'single-bladed instrument' semantic feature, but differ in manner. The manner distinctions are summarized in Table 1.

(3) Breaking with a hammer-(like) instrument. These events are labeled with three verbs: chui2 'hammer', za2 'pound', and da3 'hit'.

(4) Pulling on a flexible 2-D object (e.g., cloth, paper) with hands or a hand(-like) instrument. These events are labeled with sil 'tear, rip'.

(5) Bending or pulling on a linear (usually rigid) object (e.g., stick, carrot) with hands or a hand-like instrument. These events are labeled with four different verbs: zhe2 'bend.by.hand', bail 'bend.by.hand', jiul 'pluck', che3 'pull, stretch'. Zhe2 and bail refer to actions of pulling down circumpivotally on a linear object and they can mostly be used interchangeably. But the linear object may be prototypically thinner when zhe2 is used than when bail is used. 
Table 1. Mandarin 'cutting with single blade' verbs in the elicited data

\begin{tabular}{ll}
\hline Verbs & Glosses \\
\hline qie1 & 'do cutting with a single blade or blade-like instrument' \\
kan3 & 'do cutting with a single blade or blade-like instrument with force' \\
duo4 & 'do chopping, dicing, repeatedly' \\
zhan3 & 'do chopping, cutting cleanly' (often in literary use) \\
pi1 & 'do hacking, cutting with force and usually into halves, cleave' \\
po4 & 'dissect, cut carefully' \\
ge1 & 'do cutting with a single blade or single-blade-like instrument slowly, duratively, \\
& back and forth' \\
zao2 & 'do cutting with a chisel' \\
chuo1 & 'do cutting with a sharp pointed instrument' \\
jul & 'do cutting with a saw in a sawing manner, back and forth'
\end{tabular}

On the basis of the five event clusters just described, we can identify the following semantic features as important for distinguishing Mandarin C\&B action verbs:

- Instrument: hand(-like) instrument vs. instruments other than hand(-like) instrument (e.g., knife, scissor). This distinction is reflected in Chinese orthographical representations: verbs involving cutting or breaking by hand share the same radical $f$ or 手, which means 'hand', while verbs involving a single- or a double-bladed instrument share the radical 刀, which means 'knife'. Some of these 'instrument verbs' have an associated noun counterpart that names the instrument: e.g., jian3 'cut.with.scissor(-like) instrument' and jian3-zi 'scissor-noun.suffix', chuiz 'hammer.with.hammer(-like) instrument' and chui2-zi 'hammer-noun.suffix', zao2 'chisel' and $z a o 2-z i$ 'chiselnoun.suffix', ju4 'saw' and ju4-zi 'saw-noun.suffix'.

- Manner: cutting or breaking forcefully, e.g., kan3 vs. qiel (cf. Table 1). In situations where a certain instrument and a certain manner are both involved, manner usually overrides instrument in the selection of a C\&B action verb. For example, cutting with an axe in a sawing manner is called gel or ju4, rather than kan3 (see Table 1 for glosses).

- Features of the affected object: flexible 2-D objects (paper, cloth, etc.) and rigid linear objects (baguette, stick, etc.).

A single verb may show more than one of the features listed above. For example, instrument + object feature + manner: sil 'do tearing action on flexible 2-D object by hand(-like) instrument in pulling manner'; instrument + manner: pil 'do.hacking, cutting.with.force (usually into halves), cleave'. 
Mandarin does not have an overarching generic verb like cut that can be used across events like slicing, hacking, chopping, slashing, trimming, and sawing. Rather, a specific $\mathrm{C} \& \mathrm{~B}$ verb must be selected on the basis of the manner or instrument involved. For example, it is infelicitous to use qiel 'cut.with.single-bladed instrument' for an event where someone hacks at a tree branch; kan3 'cut.with.a.single-bladed instrument.with. force' must be used instead.

\subsection{Semantics of $C \& B$ result verbs $\left(V_{2} s\right)$}

Mandarin has fewer $\mathrm{C} \& \mathrm{~B}$ result verbs than $\mathrm{C} \& \mathrm{~B}$ action verbs. In the correspondence analysis plot, there are five core result verbs (verbs that were used for at least two stimuli) and they fall into three clear clusters:

(1) Kail 'be.open' or 'be.apart'; duan4 'be.broken, of long objects broken crosswise'. These verbs were used for the same group of stimuli. All duan4 events are also kail events, but the reverse does not hold, since kail events include separations of objects that are not necessarily long or broken crosswise.

(2) Sui4 'be.in.pieces'; lan4 'be.in.pieces, mashed, tattered or rotten, unusable'.

(3) Po4 'be.broken (of any non-linear object); general destruction of the integrity of an object; be.wounded'.

These result verbs can be seen to differentiate C\&B events along the following semantic dimensions:

- Features of the affected object (linear objects vs. others).

- State or degree of being broken (e.g., suit 'be in pieces' vs. po4 'be broken').

- Direction of the separation: crosswise vs. in some other direction (e.g., duan4 'be broken (of long objects broken crosswise)'.

It is also worth noting that path verbs, such as xia4 'descend', or xia4-lai2 'descend-come', can also be used to express the caused state change (although with the current set of stimuli, path verbs were only used marginally). For example, tal qiel-xia4 le yu2tou2 'she cut.with.single.bladedescend PFV fish.head' (she cut off the head of the fish).

If we compare the action verb and result verb event categories, we see that the sub-events picked out by the result verbs crosscut the sub-event categories of the action verbs, since the choice of a result verb depends solely on the semantic features discussed above, and is independent of the $\mathrm{C} \& \mathrm{~B}$ action used to bring about the result. 


\section{Argument structure}

It has long been noted that English $\mathrm{C} \& \mathrm{~B}$ verbs differ from one another syntactically: break verbs but not cut verbs undergo the causativeinchoative alternation (He broke/cut the rope vs. The rope broke/*cut), while cut verbs but not break verbs appear in the conative construction (He cut/broke the rope vs. He cut/*broke at the rope). Such syntactic differences are argued to be semantically determined: verbs that specify the causing subevent do not participate in the causative-inchoative alternation: cut verbs specify the means or manner involved in the causing subevent, while break verbs provide no specific information about how the state change comes about, rather they specify the result sub-event (Levin 1993; Levin and Rappaport Hovav 1995). The semantic dichotomy between $\mathrm{C} \& \mathrm{~B}$ verbs is argued to hold crosslinguistically (Guerssel et al. 1985). Let us examine the situation in Mandarin.

Action verbs can all appear in both transitive and intransitive constructions:

$$
\begin{array}{lll}
\text { a. Wo1 qie1 } & \text { le } & \text { ping2guo3. } \\
\text { I cut.with.single.blade PFV } & \text { apple } \\
\text { 'I cut the apple.' } & & \\
\text { b. Ping2guo3 qie1 } & \text { le. } \\
\text { apple cut.with.single.blade } & \text { PFV } \\
\text { 'The apple cut.' } &
\end{array}
$$

Sentences like (7b) resemble the inchoative construction superficially, since the affected object appears in the subject position and the cause is left unexpressed. But such sentences are not real inchoatives. (1) An inchoative use encodes a state change without specifying its cause. The verb qiel, as discussed in Section 3, specifies a sharp instrument, i.e., entails a causing subevent. (2) Intransitive uses of qiel verbs are incompatible with the phrase zi4ji3 'by itself' (cf. Cheng and Huang 1995), in the sense of 'without external help' (i.e., in the absence of an external cause):

$\begin{array}{lll}\text { *Ping2guo3 } & \text { zi4ji3 qie1 } & \text { le. } \\ \text { apple } & \text { self cut.with.single.blade } & \text { PFV } \\ \text { 'The apple cut by itself.' } & \end{array}$

So sentences like (7b) do not involve an inchoative interpretation, but entail the existence of an implicit causing sub-event. Such sentences may involve argument ellipsis, middle voice reading or passive reading: the external argument of qiel is understood, but not mentioned, as in English middles like 'this bread cuts easily', or passives like 'this bread is cut'. 
The crucial point for the current discussion is that such sentences are not inchoatives. $^{7}$

The ostensibly intransitive use therefore does not change the verb's lexical meaning and argument structure. Mandarin action verbs resemble English cut verbs verbs in that both types of verbs specify a causing subevent associated with state change, neither allows an external cause to be eliminated, and neither participates in the causative-inchoative alternation. The verbs are basically causative (dyadic), selecting an agent and a patient in their argument structure.

Now let us consider $C \& B$ result verbs. Unlike action verbs, these must be intransitive when they occur alone (i.e., not as part of a compound verb): stick be.broken PFV
'The stick broke.'
a. Gun4zi duan4 le.
b. *Wo3 duan4 le gun4zi. I be.broken PFV stick 'I broke the stick.'

The external cause in (9a) is left unspecified and the sentence admits an inchoative reading (state change is presented as occurring spontaneously). These verbs are compatible with the phrase zi4ji3 'by itself':

$\begin{array}{llll}\text { Gun4zi } & \text { zi4ji3 } & \text { duan4 } & \text { le } \\ \text { stick self } & \text { be.broken } & \text { PFV } \\ \text { 'The stick broke by itself.' } & \end{array}$

Result verbs resemble English break verbs to some degree: both specify a state or state change but leave the causing subevent open; both can appear in the inchoative construction. But Mandarin result verbs differ crucially from English break verbs in that they cannot be directly used as causatives.

RVCs lexicalize both the causing sub-event and the state change subevent. Like action verbs, they can appear in both transitive/causative and intransitive constructions, as in (11):
a. Wo3
bail-duan4 le gun4zi. I bend-be.broken PFV stick 'I bent-broke the stick.'
b. Gun4zi bail-duan4 le. stick bend-be.broken PFV 'The stick bent-broke.'


Since RVCs specify both the cause and the state change, neither sub-event can be eliminated. This is evidenced by the incompatibility of an RVC with the phrase zi4ji3 'by itself', which implies the absence of an external cause:

$\begin{array}{ll}\text { *Gun4zi zi4ji3 bail-duan4 } & \text { le } \\ \text { stick by.itself } & \text { bend-be.broken } \\ \text { 'The stick bent-broke by itself.' }\end{array}$

So sentences with RVCs entail a causing sub-event, even if it is left unexpressed, as in (11b). Cheng and Huang (1995) suggest that intransitive uses of RVCs are derived ergatives (also termed pseudo-passives) that manifest features of middle voice constructions. In this sense, RVCs are like action verbs (cf. 7b): both involve a causing sub-event and neither allows an inchoative interpretation.

To summarize, simplex action verbs and RVCs are basically causative and they cannot undergo detransitivization. Simplex result verbs are basically intransitive, and allow only inchoative or stative interpretations. For result verbs to causativize, they must be compounded with an action verb $^{8}$ (a valency-changing operation, Bohnemeyer this issue). This means that the causative-inchoative alternation is not applicable within the classes of action verbs, result verbs, or RVCs. Rather, it exists between a result verb, i.e., $\mathrm{V}_{2}$ of an $\mathrm{RVC}$, (inchoative) and an RVC (its causative counterpart), as exemplified in tal qiel-duan4 le shen $2 z i$ 'he cut.with .single.blade-be.broken PFV rope' vs. shen2zi duan4 le 'rope be.broken PFV'.

The analysis of the argument structure of Mandarin C\&B verbs thus supports the claim that transitivity alternation patterns are semantically determined (Guerssel et al. 1985; Levin and Rappaport Hovav 1995), and that verbs that encode instrument or manner information cannot participate in causative-inchoative alternations. Semantically, action verbs and RVCs are both specific about the causing sub-event, and therefore do not allow inchoative uses. Result verbs, in contrast, specify only the state-change sub-event, and are therefore compatible with inchoative uses. However, Mandarin C\&B verbs suggest at least a three-way distinction of C\&B verbs with an additional verb type, RVCs - the "cut-break" verbs-rather than the two-way distinction between cut and break verbs (Guerssel et al. 1985; Levin and Rappaport Hovav 1995, see Ameka and Essegbey, this issue, for a four-way distinction in Ewe).

The differences between Mandarin and English C\&B verbs can be displayed schematically on a continuum, as shown in Figure 1. The left end of the continuum represents the encoding of the action sub-event only, 


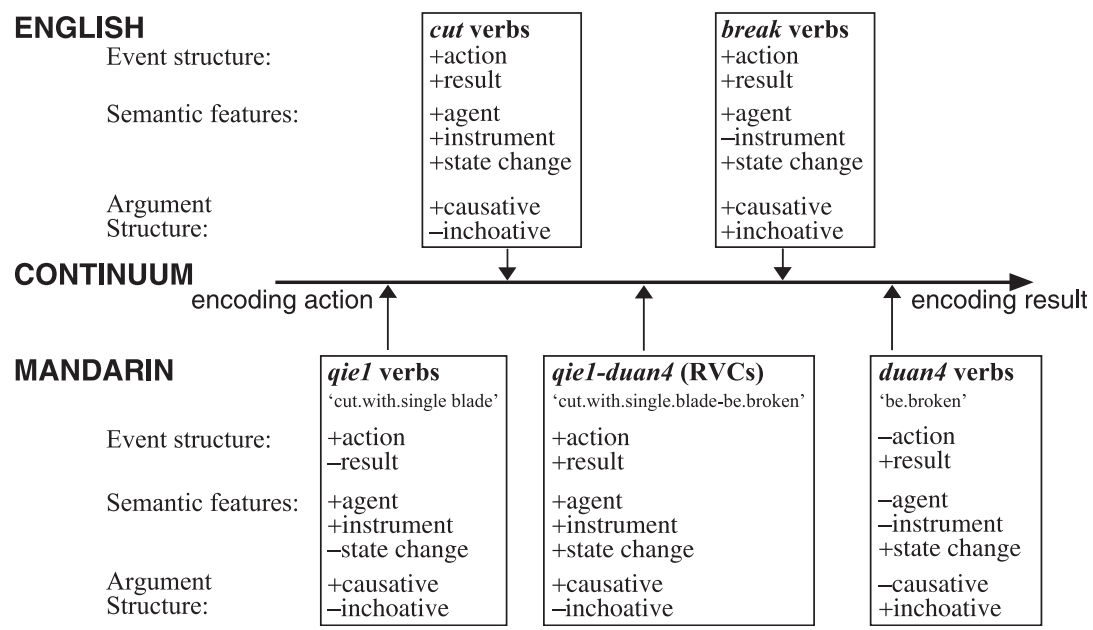

Figure 1. Comparison of $C \& B$ predicates in English and Mandarin

the right end the result sub-event only, and between the two extremes predicates encoding both the action and the result sub-events (i.e., English $\mathrm{C} \& \mathrm{~B}$ verbs and Mandarin RVCs). The relative positioning of the verb types on the continuum depicts which specific aspect(s) of a $\mathrm{C} \& \mathrm{~B}$ event are encoded in the two languages, reflecting the semantic features and the argument structure of the verbs.

\section{Conclusions}

Mandarin encodes $\mathrm{C} \& \mathrm{~B}$ events with three types of verbs: verbs that specify the action sub-event only, verbs that specify the result sub-event only, and RVCs that specify both. Action verbs and result verbs do not simply mirror each other semantically (i.e., together, they do not have meanings like "break something broken"). Rather, each verb provides an essential component of a C\&B event. Action verbs are differentiated on the basis of instrument, manner, and properties of the affected object, and result verbs are distinguished on the basis of properties of the affected object, the resultant state, and the direction of cutting or breaking (across a long axis or not). Mandarin action verbs, like English cut verbs, are dyadic in their argument structure, and do not undergo detransitivization. Mandarin result verbs, on the other hand, are intransitive and do not specify an external cause, but, unlike English break verbs, they are only monadic and cannot occur alone as transitive causatives. RVCs also do not alternate between causative and inchoative readings, as they entail 
an external cause (specified by $\mathrm{V}_{1}$ ), even if the argument expressing it is omitted, as in a middle-voice or passive construction.

Received 1 December 2004

Revision received 12 July 2006
Max Planck Institute for

Psycholinguistics, Nijmegen,

The Netherlands

\section{Notes}

* Contact: Jidong Chen, Department of Linguistics, 5245 North Baker Ave, M/S PB92, California State University, Fresno, CA 93740-8001, USA. Email: 〈jchen@csufresno .edu $>$. I wish to express my thanks to Melissa Bowerman, Penelope Brown, Bhuvana Narasimhan, and Asifa Majid for insightful discussions, and many readings and comments on earlier versions of this paper. I also thank all the Chinese participants of my experiment.

1. The gloss of duan4 is not precise, since the word has no exact counterpart in English. Duan 4 applies only to the crosswise breaking of linear objects, and it is only intransitive. The gloss 'be.broken' makes duan4 sound stative (as in the stick is broken), but duan 4 can also have an eventive reading (as in the stick broke). The short gloss 'be.broken' is adopted for convenience. This difficulty in glossing also exists for RVCs with a $\mathrm{V}_{2}$ that is in other contexts an adjective, such as hong2 'red' in tu2-hong2 'paint-red'.

2. The numbers mark tones. Abbreviation used in the glosses: PFv-perfective.

3. The terms action verbs and result verbs are used to refer to the verbs that encode the action and the result sub-events of C\&B events.

4. The full stimulus set includes 61 videoclips, but only the 43 core cutting and breaking clips will be considered here.

5. The symbol \# indicates semantic anomaly.

6. The short gloss 'bend.by.hand(-like).instrument' is adopted for convenience since Mandarin bail does not entail the state change of becoming bent. It only refers to the action of pulling down circumpivotally on a linear object.

7. The status of such sentences is open for further study. Readers may refer to Bohnemeyer (this issue) for a discussion of this ambiguity in other languages.

8. Diachronically, result verbs have undergone a semantic shift from being monomorphemic causatives to being inchoatives/statives. For example, result verbs such as sui4 'be.in.pieces' were used as causatives in early classical Chinese (around $500 \mathrm{BC}$ to 200 BC) (Jiang 1999; Li 1993), but they have gradually undergone a process of decausativization. In modern Mandarin, they must be compounded with an action verb to receive a causative interpretation.

\section{References}

Ameka, Felix, and James Essegbey

this issue Cut and break verbs in Ewe and the causative alternation construction. Cognitive Linguistics 18(2), 241-250.

Bohnemeyer, Jürgen

this issue Morpholexical relatedness and the argument structure of verbs of cutting and breaking. Cognitive Linguistics 18(2), 153-177. 
Bohnemeyer, Jürgen, Melissa Bowerman, and Penelope Brown

2001 Cut and break clips. In Levinson, Stephen C., and N. J. Enfield (eds.), Field Manual 2001, Language and Cognition Group, Max Planck Institute for Psy-

Chao, Yuen-Ren cholinguistics. Nijmegen: MPI, 90-96.

1968 A Grammar of Spoken Chinese. Berkeley: University of California Press.

Cheng, Lisa Lai-Shen, and C. T. James Huang

1994 On the argument structure of resultative compounds. In Chen, Matthew, and Ovid Tzeng (eds.), In Honor of William Wang: Interdisciplinary Studies

Greenacre, Michael J. on Language and Language Change. Taipei: Pyramid Press, 87-221.

1984 Theory and Applications of Correspondence Analysis. London: Academic press.

Guerssel, Mohamed, Kenneth Hale, Mary Laughren, Beth Levin, and Josie White Eagle

1985 A crosslinguistic study of transitivity alternations. In Eilfort, William H., Paul D. Kroeber, and Karen L. Peterson (eds.), Papers from the Parasession on Causatives and Agentivity at the 21st Regional Meeting. Chicago: Chicago Linguistic Society, 48-63.

Jiang, Shaoyu

1999 Hanyu dongjieshi chanshend de shidai [The time of the emergence of Chinese resultatives]. Guoxue Yanjiu [Journal of the Study of Chinese] 6, $240-262$.

Levin, Beth

1993 English Verb Classes and Alternations. Chicago: University of Chicago Press.

Levin, Beth, and Malka Rappaport Hovav

1995 Unaccusativity: At the Syntax-Lexical Semantics Interface. Cambridge, MA: MIT press.

Li, Charles N., and Sandra A. Thompson

1981 Mandarin Chinese: A Functional Reference Grammar. Berkeley, Los Angeles, CA: University of California Press.

Li, Fengxiang

1993 A Diachronic Study of V-V Compounds in Chinese. Unpublished doctoral dissertation, State University of New York at Buffalo.

Li, Ping, and Yasuhiro Shirai

2000 The Acquisition of Lexical and Grammatical Aspect. Berlin/New York: Mouton de Gruyter.

Majid, Asifa, Melissa Bowerman, Miriam van Staden, and James S. Boster

this issue The semantic categories of cutting and breaking events: A crosslinguistic

Smith, Carlotta perspective. Cognitive Linguistics. 18(2), 133-152.

1997 The Parameters of Aspect (2nd ed.). Dordrecht: Kluwer Academic Publishers.

Tai, J. H-Y

1984 Verbs and times in Mandarin Chinese: Vendler's four categories. In Testen,

David, Veena Mishra, and Joseph Drogo (eds.), Papers from the Parasession

on Lexical Semantics of the 20th Regional Meeting of the Chicago Linguistic

Society. Chicago: Chicago Linguistics Society, 289-296.

Talmy, Leonard

2000 Toward a Cognitive Semantics. Cambridge, MA: MIT Press. 

Copyright of Cognitive Linguistics is the property of Walter de Gruyter GmbH \& Co. KG. and its content may not be copied or emailed to multiple sites or posted to a listserv without the copyright holder's express written permission. However, users may print, download, or email articles for individual use. 